\title{
Ocular Evaluation in Patients with Chronic Kidney Disease- A Hospital Based Study
}

\author{
Mithun Thulasidas ${ }^{1 *}$ and Hrishikesh Amin² \\ ${ }^{1}$ Resident, Department of Ophthalmology, K S Hegde Medical Academy, India \\ 2Professor, Department of Ophthalmology, K S Hegde Medical Academy, India
}

\section{Research Article}

Volume 3 Issue 5

Received Date: June 22, 2018

Published Date: July 25, 2018

*Corresponding author: Mithun Thulasidas, Resident, Department of Ophthalmology, K S Hegde Medical Academy, "Parvathy" House Chamravattom P.0 Tirur Malappuram, Kerala-676102, India, Tel: 7406298745; Email: mithun.thulasidas@gmail.com

\section{Abstract}

Background: Chronic kidney disease (CKD) affects every organ system including the eye.

The aim of the study was to assess the ocular status and correlating the findings with moderate, severe and ESRD (EndStage Renal Disease) stages of CKD.

Methodology: We conducted a cross-sectional, non-interventional, and descriptive and hospital based study involving 288 eyes of 144 patients who were referred to Ophthalmology department, after being diagnosed as CKD cases, at K S Hegde Hospital.

Results: The major causes of CKD were found to be hypertension (53.4\%), combined hypertension and diabetes (19.4\%) and diabetes (15.9\%). 33\% of total eyes had vision < 6/18. The causes for visual impairment were maculopathy in $13.5 \%$ followed by cataract in $11.1 \%$ and proliferative diabetic retinopathy in $8 \%$. Anterior segment findings include conjunctival pallor in $56.9 \%$, pinguecula in $12.2 \%$, cataract in $11.1 \%$, lid oedema in $3.5 \%$, and dry eye in $5.6 \%$ and corneal calcification in $1.4 \%$. Mean intraocular pressure was within normal limits. Major posterior segment findings included hypertensive retinopathy in $49.3 \%$ followed by diabetic retinopathy in $33.3 \%$ and maculopathy in $13.5 \%$. 57 out of 105 cases of hypertensive retinopathy and 27 out of 51 cases of diabetic retinopathy were detected for the first time, thus showing the importance of ocular evaluation in patients with CKD.

Conclusion: Ocular pathology is common among patients diagnosed with CKD. Regular ocular examination is warranted in patients with CKD so that necessary advice and treatment can be given before they lose their vision irreversibly.

Keywords: Chronic Kidney Disease; Hypertension; Diabetes; Retinopathy; Cataract

Abbreviations: CKD: Chronic Kidney Disease; ESRD: End-Stage Renal Disease; HTN: Hypertension; TRD: Tractional Retinal Detachment; RP: Retinitis Pigmentosa;
CSME: Clinically Significant Macular Edema; CME: Cystoid Macular Edema; ARMD: Age Related Macular 
Degeneration; FTMH: Full thickness Macular Hole; ERM: Epiretinal Membrane.

\section{Introduction}

CKD is a growing global health problem affecting 10$16 \%$ of the adult population in Asia. CKD affects almost all organs of the body, including the eyes [1]. Richard Bright first associated renal disease with blindnes, later it was recognized that uremic retinitis is the manifestation of hypertension [2]. The Visual system is affected as a result of Uraemia, Metabolic imbalances, Hypertension or Hemodialysis treatment [3]. Major Ocular anterior segment findings related to CKD are lid oedema and conjunctival pallor associated with increased serum lipids $[4,5]$. Calcification in cornea and conjunctiva may occur due to secondary hyperparathyroidism. Inflammatory reactions of conjunctiva and episclera may be associated with sudden increase in calcium [2]. Degenerative changes of conjunctiva such as pinguecula are seen frequently [6,7]. Early cataractogenesis occur due to increased intracellular calcium and deposition of calcium in lens [8]. Accelerated hypertension can lead to optic disc oedema [9]. Blindness due to Proliferative retinopathy or maculopathy is more common in patients with diabetic retinopathy and CKD compared with normoalbuminuric patients [10]. Bullous retinal detachment could be due to deranged metabolism, hypertension and retinal pigment epithelial dysfunction [11]. Hemodialysis could lead to alterations in lacrimal secretion, fundus changes like arteriolar narrowing and paleness $[12,13]$. Renal and Retinal circulations share similar anatomic, physiologic and pathologic features, hence assessment of retinal microvasculature gives the oppurtunity to find early mirocirculatory changes associated with CKD. Retinopathy is often asymptomatic in treatable stage, if not diagnosed early could increase the risk of visual loss [14-17].

Aim: Aim of the study was to assess the ocular status associated with CKD.

\section{Objectives}

1. Examination of eye including vision, anterior segment, intraocular pressure measurement and posterior segment 2. Correlating ocular findings with moderate, severe and ESRD (End-Stage Renal Disease) stages of CKD

\section{Methodology}

Study Design: A cross-sectional, non-interventional, descriptive and hospital based study
Study Setting: Justice K.S.Hegde Charitable Hospital. Study Population: Cases of CKD attending in Nephrology Department, consecutive cases were collected and stratified into different grades of CKD.

Study Period: The study was carried out from October 2015- June 2017.

Sample Size: The study involved 288 eyes of 144 patients who were diagnosed cases of CKD referred to Ophthalmology department from Nephrology.

Sample size was calculated according to the formula, $\mathrm{n}=$ $4 \mathrm{PQ} / \mathrm{d}^{2}$

the technique of estimation of proportion (prevalence) $\mathrm{P}$ was used, $Q=1-P$, the anticipated proportion was $90 \%$, the level of significance is taken as $5 \%$, precision was considered as 4 , hence $n=144$.

\section{Sample Selection}

- Selection Method : Consecutive and stratified

\section{Inclusion Criteria}

All cases diagnosed as CKD ( $>3$ months duration) graded into moderate, severe and ESRD.

Cases are classified on the basis of KDOQI [18].

(Kidney Disease Outcomes Quality Initiative)

- Moderate - GFR 30-59ml/min $/ 1.73 \mathrm{~m}^{2}$

- Severe - GFR $15-29 \mathrm{ml} / \mathrm{min} / 1.73 \mathrm{~m}^{2}$

- ESRD - GFR $<15 \mathrm{ml} / \mathrm{min} / 1.73 \mathrm{~m}^{2}$ or Kidney failure treated by Dialysis

Glomerular filtration rate (GFR) calculation using MDRD

(Modification of Diet in Renal Diseases) formula [19].

GFR $=186 \times$ serum creatinine ${ }^{-1.154} \times$ age $^{-0.203} \times[1.210$ if black] $x$ [0.742 if female]

Exclusion Criteria: Cases of reversible renal failure (mild)

Informed Consent was obtained from each patient according to the tenets of the Declaration of Helsinki.

A detailed history, both ocular and medical was elicited from all patients including past, personal and family history. General examination including physical condition of the patient and basic vitals were also recorded and documented. The patients underwent a detailed ophthalmic examination including visual acuity testing with best corrected visual acuity. Dry eye was diagnosed using Schirmer test.

\section{Diagnosis of Dry Eye}

Schirmer I: $<10 \mathrm{~mm}$ in 5 minutes or $<10 \mathrm{~mm}$ in 2 minutes. 
Schirmer I with topical anaesthesia: $<5.5 \mathrm{~mm}$ in 5 minutes $[20,21]$.

Intraocular pressure was measured using Goldmann applanation tonometer .

Pupils were dilated with Tropicamide eye drops for fundus evaluation using

(a) Direct Ophthalmoscope

(b) Slit lamp biomicroscopy with 90 diopter lens

(c) Indirect ophthalmoscopy with 20 diopter lens

Hypertensive Retinopathy is graded on the basis of Scheie classification [22].

Diabetic Retinopathy is classified on the basis of early treatment Diabetic Retinopathy Study (ETDRS) [23].

Glaucoma suspect is defined as cup-to-disc ratio of $>/=$ 0.6 or asymmetric cupping $>0.2$ between 2 eyes.

\section{Statistical Analysis}

The results were statistically analysed.

Statistical analysis was performed on SPSS version 17.0 for Windows.

Chi-square tests, Fishers exact test were used for analysing the data.

A probability value (' $\mathrm{p}$ ' value) of $<0.05$ was considered as statistically significant.

\section{Results}

A total of 144 patients of (CKD) were included. The sample size in each grade of CRF were as follows: moderate, 92 cases (64\%); severe, 35 cases (24\%); ESRD, 17 cases (12\%). A total of 144 patients of (CKD) were included. The sample size in each grade of CRF were as

follows: moderate, 92 cases (64\%); severe, 35 cases (24\%); ESRD, 17 cases (12\%).

\section{Grading of CKD}

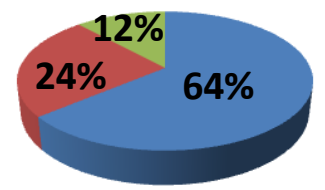

Moderate
Severe
ESRD

$\mathrm{x}^{2}=63.875, \mathrm{p}=.0001$, Highly significant (HS)

Figure 1: Grading of CKD of the study population.

The commonest cause of CKD was hypertension (HTN), 77 out of 144 patients (53.4\%), followed by combined HTN and diabetes in 28 patients (19.4\%), diabetes in 23 patients (15.9\%) glomerulonephritis (6.3\%) and other causes including renal calculi (4.9\%).

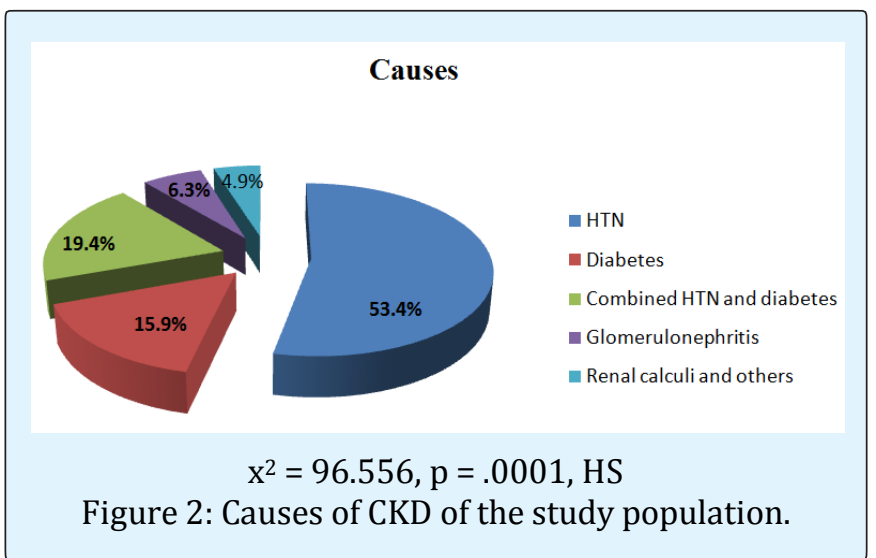

\begin{tabular}{|c|c|c|c|c|c|}
\hline Stages of CKD & Moderate & Severe & ESRD & Total & \% of total eyes \\
\hline $\begin{array}{c}\text { Visual acuity } \\
\text { (WHO criteria) }\end{array}$ & & & & & \\
\hline $\begin{array}{c}\text { Good vision } \\
>/=6 / 18\end{array}$ & $\begin{array}{c}180 \\
(93.80 \%)\end{array}$ & $\begin{array}{c}12 \\
(6.30 \%)\end{array}$ & - & $\begin{array}{c}192 \\
(100 \%)\end{array}$ & $66.70 \%$ \\
\hline $\begin{array}{c}\text { Impaired vision } \\
6 / 60-6 / 24\end{array}$ & $\begin{array}{c}52 \\
(7.10 \%)\end{array}$ & - & $\begin{array}{c}56 \\
(100 \%)\end{array}$ & $19.40 \%$ \\
\hline $\begin{array}{c}\text { Legally blind } \\
<6 / 60\end{array}$ & - & $\begin{array}{c}6 \\
(15 \%)\end{array}$ & $\begin{array}{c}34 \\
(85 \%)\end{array}$ & $\begin{array}{c}40 \\
(100 \%)\end{array}$ & $13.90 \%$ \\
\hline Total eyes & $\begin{array}{c}784 \\
(63.90 \%)\end{array}$ & $\begin{array}{c}70 \\
(24.30 \%)\end{array}$ & $\begin{array}{c}34 \\
(11.80 \%)\end{array}$ & $(100 \%)$ & $100 \%$ \\
\hline
\end{tabular}

Table 1: BCVA in the eyes among different stages of CKD. 
Mean age of total patients was 55.9 years with a standard deviation of 7.5 (ranging from 42-70 years) and male: female ratio in total was 1.3:1 Only 62 patients $(43 \%)$ had a previous history of eye check up.
Fishers exact test $\mathrm{p}=0.0001$, HS According to WHO criteria (76), 66.7\% had good vision, $19.4 \%$ were visually impaired and $13.9 \%$ had vision < $6 / 60$. Significant anterior segment findings were seen in 129 eyes (44.8\%) among moderate stage and all cases $(100 \%)$ among severe and ESRD categories.

\begin{tabular}{|c|c|c|c|c|c|}
\hline Stages of CKD & Moderate & Severe & ESRD & Total & $\%$ of total eyes \\
\hline \multicolumn{6}{|c|}{ Ocular anterior segment findings } \\
\hline Lid oedema & $\begin{array}{c}2 \\
(20 \%) \\
\end{array}$ & $\begin{array}{c}4 \\
(40 \%) \\
\end{array}$ & $\begin{array}{c}4 \\
(40 \%) \\
\end{array}$ & $\begin{array}{c}10 \\
(100 \%)\end{array}$ & $\begin{array}{c}3.5 \% * * \\
(p=0.0001)\end{array}$ \\
\hline Conjunctival pallor & $\begin{array}{c}112 \\
(68.30 \%)\end{array}$ & $\begin{array}{c}40 \\
(24.40 \%)\end{array}$ & $\begin{array}{c}12 \\
(7.30 \%)\end{array}$ & $\begin{array}{c}164 \\
(100 \%)\end{array}$ & $\begin{array}{c}56.9 \% * \\
(p=0.023)\end{array}$ \\
\hline Pinguecula & $\begin{array}{c}11 \\
(31.40 \%) \\
\end{array}$ & $\begin{array}{c}15 \\
(42.90 \%) \\
\end{array}$ & $\begin{array}{c}9 \\
(25.70 \%) \\
\end{array}$ & $\begin{array}{c}35 \\
(100 \%) \\
\end{array}$ & $\begin{array}{c}12.2 \% * \\
(\mathrm{p}=0.015)\end{array}$ \\
\hline Corneal calcification & - & $\begin{array}{c}2 \\
(50 \%)\end{array}$ & $\begin{array}{c}2 \\
(50 \%) \\
\end{array}$ & $\begin{array}{c}4 \\
(100 \%)\end{array}$ & $\begin{array}{c}1.4 \% * * \\
(p=0.001)\end{array}$ \\
\hline Dry eyes & $\begin{array}{c}4 \\
(25 \%) \\
\end{array}$ & $\begin{array}{c}6 \\
(37.50 \%) \\
\end{array}$ & $\begin{array}{c}6 \\
(37.50 \%) \\
\end{array}$ & $\begin{array}{c}16 \\
(100 \%)\end{array}$ & $\begin{array}{c}5.6 \% * * \\
(p=0.003)\end{array}$ \\
\hline Cataract & $\begin{array}{c}4 \\
(12.50 \%) \\
\end{array}$ & $\begin{array}{c}15 \\
(46.90 \%) \\
\end{array}$ & $\begin{array}{c}13 \\
(40.60 \%)\end{array}$ & $\begin{array}{c}32 \\
(100 \%)\end{array}$ & $\begin{array}{c}11.1 \%{ }^{* *} \\
(p=0.0001)\end{array}$ \\
\hline Normal & $\begin{array}{c}55 \\
(100 \%)\end{array}$ & - & - & $\begin{array}{c}55 \\
(100 \%)\end{array}$ & $\begin{array}{c}19.1 \%{ }^{* *} \\
(p=0.0001)\end{array}$ \\
\hline
\end{tabular}

Table 2: Ocular anterior segment findings in the eyes among different stages of CKD.

*Significant, with level of significance: $\mathrm{P}<0.05$ at $95.0 \%$ confidence limit, ${ }^{* *}$ highly significant (HS), using chi-square tests and fishers exact test.

\begin{tabular}{|c|c|c|c|c|c|}
\hline Stages of CKD & Moderate & Severe & ESRD & Total & $\%$ of total eyes \\
\hline \multicolumn{6}{|l|}{ Ocular posterior segment findings } \\
\hline HR & $\begin{array}{c}64 \\
(45.10 \%)\end{array}$ & $\begin{array}{c}44 \\
(31 \%)\end{array}$ & $\begin{array}{c}34 \\
(23.90 \%)\end{array}$ & $\begin{array}{c}142 \\
(100 \%)\end{array}$ & $\begin{array}{c}49.3 \% * * \\
(p=0.0001)\end{array}$ \\
\hline DR & $\begin{array}{c}24 \\
(25 \%)\end{array}$ & $\begin{array}{c}38 \\
(39.60 \%)\end{array}$ & $\begin{array}{c}34 \\
(35.40 \%)\end{array}$ & $\begin{array}{c}96 \\
(100 \%)\end{array}$ & $\begin{array}{c}33.3 \% * * \\
(p=0.0001)\end{array}$ \\
\hline Maculopathy & - & $\begin{array}{c}28 \\
(71.80 \%)\end{array}$ & $\begin{array}{c}11 \\
(28.20 \%)\end{array}$ & $\begin{array}{c}39 \\
(100 \%)\end{array}$ & $\begin{array}{c}13.5 \% * * \\
(\mathrm{p}=0.0001)\end{array}$ \\
\hline VH & - & $\begin{array}{c}11 \\
(55 \%)\end{array}$ & $\begin{array}{c}9 \\
(45 \%)\end{array}$ & $\begin{array}{c}20 \\
(100 \%)\end{array}$ & $\begin{array}{c}6.9 \% * * \\
(p=0.0001)\end{array}$ \\
\hline $\begin{array}{c}\text { Tractional retinal detachment } \\
\text { (TRD) }\end{array}$ & - & $\begin{array}{c}2 \\
(66.70 \%) \\
\end{array}$ & $\begin{array}{c}1 \\
(33 \%) \\
\end{array}$ & $\begin{array}{c}3 \\
(100 \%) \\
\end{array}$ & $\begin{array}{c}1 \% * \\
(p=0.046)\end{array}$ \\
\hline Retinitis pigmentosa (RP) & - & $\begin{array}{c}2 \\
(100 \%)\end{array}$ & - & $\begin{array}{c}2 \\
(100 \%)\end{array}$ & $\begin{array}{c}0.70 \% \\
(p=0.132)\end{array}$ \\
\hline BRVO & - & $\begin{array}{c}1 \\
(100 \%)\end{array}$ & - & $\begin{array}{c}1 \\
(100 \%)\end{array}$ & $\begin{array}{c}0.40 \% \\
(p=0.372)\end{array}$ \\
\hline
\end{tabular}

*Significant, ** (HS), using chi-square tests and fishers exact test.

Table 3: Ocular posterior segment findings in the eyes among different stages of CKD.

Significant posterior segment findings were seen in 182 eyes (58.3\%), 78 eyes out of 184 eyes (42.4\%) among moderate stage and all cases among severe (70 eyes) and ESRD categories (34 eyes).
Mean IOP in 288 eyes is $13.4 \mathrm{mmHg}$ with a standard deviation of 2.2 (ranging from $6-18 \mathrm{mmHg}$ ) 


\section{Open Access Journal of Ophthalmology}

\begin{tabular}{|c|c|c|}
\hline Causes of visual impairment & Number of eyes & \% of the total eyes \\
\hline Maculopathy & $\begin{array}{c}39 \\
(40.60 \%)\end{array}$ & $13.50 \%$ \\
\hline Cataract & $\begin{array}{c}32 \\
(33.30 \%)\end{array}$ & $11.10 \%$ \\
\hline PDR & $\begin{array}{c}23 \\
(24 \%)\end{array}$ & $8 \%$ (approximately) \\
\hline RP & $\begin{array}{c}2 \\
(2.10 \%) \\
96 \\
(100 \%)\end{array}$ & $33.30 \%$ \\
\hline Total &
\end{tabular}

$\mathrm{x}^{2}=32.250, \mathrm{p}=.0001, \mathrm{HS}$

Table 4: Causes of visual impairment (BCVA $<6 / 18)$ in CKD patients.

Maculopathy and Cataract were found to be significant causes of vision loss $(<6 / 18)$.

\begin{tabular}{|c|c|c|}
\hline Maculopathy & Number of eyes & \% of the total eyes \\
\hline $\begin{array}{c}\text { Clinically Significant Macular Edema } \\
\text { (CSME) }\end{array}$ & $\begin{array}{c}13 \\
(33.30 \%)\end{array}$ & $4.50 \%$ \\
\hline $\begin{array}{c}6 \\
\text { Cystoid Macular Edema (CME) }\end{array}$ & $\begin{array}{c}6.30 \%) \\
(20.50 \%)\end{array}$ & $2.70 \%$ \\
\hline $\begin{array}{c}\text { Non-exudative (Dry) age related Macular } \\
\text { degeneration (ARMD) }\end{array}$ & $\begin{array}{c}4 \\
(10.30 \%)\end{array}$ & $1.40 \%$ \\
\hline Exudative ARMD & $\begin{array}{c}4 \\
(10.30 \%)\end{array}$ & $1.40 \%$ \\
\hline Full thickness Macular Hole (FTMH) & $\begin{array}{c}4 \\
(10.30 \%)\end{array}$ & $13.50 \%$ \\
\hline Epiretinal membrane (ERM) & $\begin{array}{c}39 \\
(100 \%)\end{array}$ & \\
\hline Total &
\end{tabular}

Table 5: Maculopathy causes for visual impairment.

\begin{tabular}{|c|c|c|c|c|}
\hline Stages of CKD & $\begin{array}{c}\text { Moderate } \\
\text { (184 eyes) }\end{array}$ & $\begin{array}{c}\text { Severe } \\
\text { (70 eyes) }\end{array}$ & $\begin{array}{c}\text { ESRD } \\
\text { (34 eyes) }\end{array}$ & $\begin{array}{c}\text { Total } \\
\text { (288 eyes) }\end{array}$ \\
\hline Grades of HR & & & - & 46 \\
\hline I & 34 & 12 & 18 & 72 \\
\hline II & 30 & 24 & 16 & 24 \\
\hline III & - & 8 & - & - \\
\hline IV & - & - & 34 & 142 \\
\hline
\end{tabular}

Table 6: Comparison of grades of HR with stages of CKD. 


\section{Open Access Journal of Ophthalmology}

\begin{tabular}{|c|c|c|c|c|}
\hline Stages of CKD & $\begin{array}{c}\text { Moderate } \\
\text { (184 eyes) }\end{array}$ & $\begin{array}{c}\text { Severe } \\
\text { (70 eyes) }\end{array}$ & $\begin{array}{c}\text { ESRD } \\
\text { (34 eyes) }\end{array}$ & $\begin{array}{c}\text { Total } \\
\text { (288 eyes) }\end{array}$ \\
\hline Grades of DR & & & 4 & 30 \\
\hline Mild NPDR & 18 & 8 & 6 & 17 \\
\hline Moderate NPDR & 6 & 5 & 8 & 17 \\
\hline Severe NPDR & - & 9 & 6 & 9 \\
\hline Very severe NPDR & - & 3 & 10 & 23 \\
\hline High risk PDR & - & 13 & 34 & 96 \\
\hline Total eyes with DR & 24 & 38 & & 2 \\
\hline
\end{tabular}

Table 7: Comparison of grades of DR with stages of CKD.

\section{Discussion}

CKD is a slowly progressive deterioration of renal function which can occur at any age group. In our study, male: female ratio in CKD was 1.3:1 which was similar to the worldwide data and different studies [24]. Deterioration of kidney function occurs at a faster rate in males with some forms of glomerulonephritis and polycystic kidney disease [2,24,25]. Mean age of 144 patients is 55.9 years with a standard deviation of 7.5 which is in consistent with the study done by Dr. Manjula MS, et al. [24]. In our study, the major causes of CKD were found to be HTN (53.4\%), combined HTN and diabetes $(19.4 \%)$ and diabetes $(15.9 \%)$ followed by glomerulonephritis in 6\% [24]. Other causes including renal calculus were seen only in $5 \%$. This is not in accordance with the study done by Dr. Manjula MS et al. where the commonest course of CKD was diabetes (32\%) followed by patients with diabetes and hypertension (29\%) [24].

Different studies done by Bajracharya $\mathrm{L}$, et al. and Dahal P, et al. revealed HTN as the major cause of CKD. $73 \%$ of patients gave history of CRF for less than 1 year $[2,25] .57 \%$ of patients have never had eye check up before. Only $43 \%$ had a previous history of ocular examination, which showed the lack of awareness about the associated ocular complications. Greater percentage of patients in ESRD (64.7\% compared to 38\% in moderate group) had a eye check up in the past which indicate ocular problems associated with advancing renal disease. $33 \%$ of the total eyes had visual acuity of less than $6 / 18$. In our study, maculopathy and cataract account for the major causes of visual impairment in 13.5\% (39 eyes) and $11.1 \%$ (32 eyes). High risk PDR was responsible for the vision loss in $8 \%$ (23 eyes). This could be compared with the study by Bajracharya L., et al. where impaired vision is found in 23 percent of eyes and maculopathy as the main cause for vision loss, followed by cataract and diabetic retinopathy. Conjunctival pallor was present in $56.9 \%$ of the total eyes which can be considered as a consistent finding in CKD, being statistically significant [2]. This could be due to low haemoglobin levels.

Lid oedema is seen only in $3.5 \%$, mainly in severe and ESRD categories, different from the study by L. Bajracharya et al. that showed a very high percentage of $63 \%$. Deranged renal function prevents efficient excretion of salt and water from the body, thus causing retention [2]. This fluid retention leads to generalised swelling comprising of pedal oedema, facial puffiness and lid oedema. Corneal calcification $(1.4 \%)$ was present in patients of severe and ESRD groups [26]. Calcification was near the temporal and nasal limbus and vision was not affected. Different studies reported calcification in 60.0 to $80.0 \%$. Calcification in cornea and conjunctiva may occur due to secondary hyperparathyroidism $[27,28]$. Degenerative conditions of conjunctiva such as pinguecula is seen in $12.2 \%$ of the total eyes, which is a frequent finding in Chronic renal failure according to a study by Pahor D, et al. Inflammatory reactions of conjunctiva and episclera may be associated with increase in calcium $[2,27] .5 .6 \%$ of the total eyes were diagnosed as dry eye which was common in severe and ESRD groups (37.5\%) compared to moderate group (25\%).

This could be due to alterations in lacrimal secretion in patients with CRF undergoing hemodialysis. Cataract was present in $11.1 \%$ of the total eyes and could be associated with increased intracellular calcium and deposition of calcium in lens [14]. The paper by Liu et al. highlighted the increased prevalence of cataracts in CKD 
and suggested that cataracts become more common as renal failure worsens but did not conclude whether CKD was important in cataract initiation or progression [2]. Diagnosis of cataract mainly in severe (46.9\%) and ESRD (40.6\%) groups compared to moderate group showed its association with progression of renal disease [29]. Mean intra ocular pressure in patients of CRF was $13.4 \mathrm{mmHg}$ with a standard deviation of 2.2 (ranging from 6$18 \mathrm{mmHg}$ ). In one of the studies done in Italy by De Marchi $S$ et al., average IOP of CKD patients was slightly less than the control group $(14.9+2 \mathrm{mmHg}$ versus $15.6+1.9 \mathrm{mmHg}$ with $\mathrm{P}=0.07$ ) [30]. Our study did not have the control group. Ocular posterior segment findings are the most important in patients with CKD and are responsible for visual impairment also. Hypertensive retinopathy was the most common finding in our study in $49.3 \%$ of the eyes. $71(67.6 \%)$ out of 105 cases diagnosed with hypertension had retinopathy changes.

Grade III HR was diagnosed only in severe and ESRD groups in our study. It was found to be proportional to progression of renal disease. The HR findings correlated well with other studies. No patients had grade IV HR in our study [2,24,25]. Hypertensive retinopathic findings are particularly severe in CKD due to effects of retained nitrogen products. DR was present in 33.3\% of the total eyes. 48 (94.1\%) out of 51 diabetic cases had DR [9]. Mild and moderate NPDR was mostly seen in moderate CKD group but, severe and very severe NPDR and PDR were seen only in severe and ESRD groups. Although not statistically proven, these data correlated well with previous studies. High risk PDR associated with VH was seen in 20 eyes in severe (11 eyes) and ESRD ( 9 eyes) grades of renal disease [2,24,31]. 3 eyes with PDR had developed TRD ( 2 eyes in severe stage and 1 eye in ESRD. A study by Mohmad et al. showed that the commonest abnormality in diabetic nephropathy patients was nonproliferative diabetic retinopathy (ranging from mild, moderate and severe). Moderate and severe proliferative diabetic retinopathy were seen in higher grades of chronic renal failure. Our results are in comparison with this study [32]. DR is invariably present in cases of diabetic nephropathy and more severe forms of retinopathy are observed with progression of renal disease.

39 eyes had maculopathy as the cause of visual impairment, only in severe and ESRD groups. Out of which, 13 eyes had clinically significant macular oedema, all of them were associated with DR. 6 eyes had CME due to various etiologies leading to impaired vision. Age related macular degeneration was seen in 12 eyes (8 eyes had dry ARMD, 4 eyes had wet ARMD) which could be due to associated risk factors like hypertension. Most of the cases in this study belonged to the age group $>55$ years, thus contributing to the development of macular degeneration. Different studies showed association of ARMD with CKD with varying results [33-35].

FTMH and ERM were also seen in 4 eyes each, responsible for visual impairment. Blindness due to maculopathy is more common in patients with diabetic retinopathy and CKD compared with normoalbuminuric patients. There was one case of retinitis pigmentosa in severe grade of renal disease, which also led to impaired vision [11]. 57 out of 105 cases of HR and 27 out of 51 cases of DR were detected for the first time. 18 patients underwent laser treatment in the retina and 11 underwent posterior vitrectomy. 21 eyes underwent successful cataract extraction.

\section{Conclusion}

Ocular pathology is common among patients diagnosed with CKD. Ocular findings could give an indication about the metabolic control of the disease process. Regular ocular examination is warranted in patients with CKD and systemic diseases so that necessary advice and treatment can be given before they lose their vision irreversibly. Awareness is needed of the potential ocular complications of the renal disease process. Measures like detailed ophthalmic examination, strict metabolic control of diabetes, and strict control of hypertension are important for a healthy living.

\section{References}

1. Gao B, Zhu L, Pan Y, Yang S, Zhang L, et al. (2011) Ocular fundus pathology and chronic kidney disease in a Chinese population. BMC Nephrology 12: 62 .

2. Bajracharya L, Shah DN, Raut KB, Koirala S (2008) Ocular evaluation in patients with chronic renal failure - a hospital based study. Nepal Med Coll J 10(4): 209-214.

3. Duke-Elders S, Dohree JH (1967) System of Ophthalmology, Vol X .1sted. London: The CV Mosby Company; chapter 4: 315-3347.

4. Ehlers N, Hansen F, Hansen H, Jensen O (2009) Corneo-conjunctival changes in uremia. Acta Ophthalmologica 50(1): 83-94.

5. Savige J, Ratnaike S, Colville D (2011) Retinal Abnormalities Characteristic of Inherited Renal 
Disease. Journal of the American Society of Nephrology 22(8): 1403-1415.

6. Klaassen-Broekema N, van Bijsterveld O (1992) Red eyes in renal failure. British Journal of Ophthalmology 76(5): 268-271.

7. Klaassen-Broekema N, van Bijsterveld OP (1995) The role of serum calcium in the development of the acute red eye in chronic renal failure. Eur J Ophthalmol 5: 712.

8. Cohen SL, Gorchein A, Hayward JA, Kennerley-Bankes JL, Petrie A, et al. (1974) Pingueculae-an association with renal failure. Queensland J Med 43(170): 281291.

9. Duane TD, Jaeger EA (1987) Duane's clinical ophthalmology. Vol Revised ed. USA: Harper and Row; Chapter 31: 1-2.

10. Ryan SJ, Schachat AP (2006) Medical Retina. $4^{\text {th }}$ (Edn.), $2^{\text {nd }}($ Vol), Philadelphia: Elservier Mosby pp: 1271-1278, 1377-1381.

11. Schrier RW, Gottschalk CW (1993) Diseases of the kidney. $5^{\text {th }}(E d n),. 1^{\text {st }}, 2^{\text {nd }}, 3^{\text {rd }}(\mathrm{Vol})$ Boston-TorontaLondon: Little Brown \& Comp, pp: 364, 1563, 2180-1.

12. Friberg TR, Eller AW (1990) Serous retinal detachment resembling central serous chorioretinopathy following organ transplantation. Graefes Arch ClinExpOphthalmol 228(4): 305-309.

13. Gass JDM (1992) Bullous retinal detachment and multiple retinal pigment epithelial detachments in patients receiving haemolialysis. Graefes Arch Clin Exp Ophthalmol 230(5): 454-458.

14. Ignat F, Davidescu L, Mota E, Godeanu L (1999) The ocular changes in patients on chronic dialysis. Oftalmologia 46(1): 23-30.

15. Demco TA, McCormick AQ, Richards JSF (1974) Conjunctival and corneal changes in chronic renal failure. Can J Ophthalmol 9(2): 208-213.

16. Klein R, Zinman B, Gardiner R, Suissa S, Donnelly SM, et al. (2005) The relationship of diabetic retinopathy to preclinical diabetic glomerulopathy lesions in type 1 diabetic patients: the Renin-Angiotensin System Study. Diabetes 54(2): 527-533.
17. Albert DM, Jacobiec FA, Azar DT, Gragoudas ES, Power SM, et al. (2000) Principles and Practice of Ophthalmology. $2^{\text {nd }}(E d n),. 2^{\text {nd }}($ Vol), Philadelphia: WB Saunders, pp: 1900-1913.

18. (2002) National Kidney Foundation: K/DOQI Clinical Practice Guidelines for Chronic Kidney Disease: Evaluation, Classification and Stratification. Am J Kidney Dis 39: S1-S266.

19. Levey AS, Bosch JP, Lewis JB, Greene T, Rogers N, et al. (1999) A more accurate method to estimate glomerular filtration rate from serum creatinine: a new prediction equation. Modification of Diet in Renal Disease Study Group. Ann Intern Med 130(6): 461470.

20. Vitali C, Moutsopoulos HM, Bombardieri S (1994) The European Community Study Group on diagnostic criteria for Sjögren's syndrome. Sensitivity and specificity of tests for ocular and oral involvement in Sjögren's syndrome. Ann Rheum Dis 53(10): 637-647.

21. Van Bijsterveld OP (1969) Diagnostic tests in the Sicca syndrome. Arch Ophthalmol 82(1): 10-14.

22. Scheie HG (1953) Evaluation of ophthalmoscopic changes of hypertension and arteriolar sclerosis. AMA Arch Ophthalmol 49(2): 117-138.

23. Early Treatment Diabetic Retinopathy Study Research Group (1991) Early Treatment Diabetic Retinopathy Study design and baseline patient characteristics: ETDRS report number 7. Ophthalmology 98(5): 741756.

24. Manjula B, Khadari M H, Velampalli S (2017) A Clinical Study of Retinal Changes in Chronic Renal Failure Patients. IOSR Journal of Dental and Medical Sciences 16(4): 31-34.

25. Dahal P, Gouli S (2015) Ocular findings in the chronic renal failure. Journal of College of Medical Sciences Nepal 10(2).

26. Gupta N, Singla A, Reddy VS, Sethi S (2015) International Journal of Advances In Case Reports 2(16): 1037-1040.

27. Pahor D, Hojs R, Gracner B (1995) Conjunctival and corneal changes in chronic renal failure patients treated with maintenance hemodialysis. Ophthalmologica 209: 14-16. 


\section{Open Access Journal of Ophthalmology}

28. Michaud PA (1978) Corneal and conjunctival deposits in the eyes of patients treated with periodic haemodialysis: Study of 47 patients. Klin Monatsbl Augenheilkd 172: 523-526.

29. Liu Y, Hung T, Lee Y, Huang M, Hsu C, et al. (2017) Association between Chronic Kidney Disease and Risk of Cataract: A Nationwide Retrospective Cohort Study. American Journal of Nephrology 45(6): 524531.

30. De Marchi S, Cecchin E, Tesio F (1989) Intraocular pressure changes during hemodialysis: prevention of excessive dialytic rise and development of severe metabolic acidosis following acetazolamide therapy. Ren Fail 11(2-3): 117-124.

31. Wong CW, Lamoureux EL, Cheng CY, Cheung GCM, Tai ES, et al. (2016) Increased Burden of Vision Impairment and Eye Diseases in Persons with Chronic Kidney Disease - A Population-Based Study. E Bio Medicine 5: 193-197.
32. Mohmad AH, Hassan A, Sidique A, Gadour MH, Hamad M, et al. (2011) Correlation between Retinopathy, Nephropathy and Peripheral Neuropathy among Adult Sudanese Diabetic Patients. Sudan Jour Med Sci 6(1): 27-32.

33. Liew G, Mitchell P, Wong TY, Iyengar SK, Wang JJ (2008) CKD increases the risk of age-related macular degeneration. J Am Soc Nephrol 19(4): 806-811.

34. Klein R, Knudtson, Lee KE, Klein BE (2009) Serum cystatin C level, kidney disease markers, and incidence of age-related macular degeneration: the Beaver Dam Eye Study. Arch Ophthalmol 127(2): 193-199.

35. Nitsch D, Evans J, Roderick PJ, Smeeth L, Fletcher AE (2009) Associations between chronic kidney disease and age-related macular degeneration. Ophthalmic Epidemiol 16(3): 181-186. 